\title{
REPENSANDO LAS TEORÍAS DE LAS RELACIONES INTERNACIONALES A COLACIÓN DEL FRACASO DE EEUU EN AFGANISTÁN. UNA MIRADA MATERIALISTA ECLÉCTICA
}

\section{RETHINKING INTERNATIONAL RELATIONS THEORIES IN LIGHT OF THE U.S. FAILURE IN AFGHANISTAN. AN ECLECTIC MATERIALIST VIEW}

\section{Eduardo M. Molina Campano}

Universidad Pablo de Olavide, Sevilla, España

emmolcam@upo.es / edula7@hotmail.com

Resumen: El interés de esta investigación radica en repensar las teorías de las Relaciones Internacionales a colación del fracaso de EEUU en Afganistán. No se trata de un análisis exhaustivo del conflicto en sí, sino de un intento por comprender el conflicto desde las teorías (neo)liberales, (neo)realistas y críticas. Mi conclusión es doble, por un lado propongo y defiendo que, -al igual que el (neo)liberalismo y el (neo)rrealismo se basan a fin de cuentas en una suerte de eclecticismo epistemológico y ontológico a la hora de planificar las acciones en política internacional-, las teorías críticas emancipatorias deberían apostar por un eclecticismo crítico materialista -más allá de las excepciones idealistas- con el objeto de superar el fraccionalismo teórico-práxico de los movimientos sociales y de los Estados subalternos; Por otro lado afirmo que el fracaso de EEUU en Afganistán y el advenimiento Talibán, fue debido, entre otras cosas -inseguridad permanente, corrupción generalizada y malas prácticas de las tropas ocupantes-, al desconocimiento de la subjetividad cultural de la población afgana que gira en torno al islam y a sus preceptos irracionalistas.

Abstract: The interest of this research lies in rethinking theories of International Relations in light of the US failure in Afghanistan. It is not an exhaustive analysis of the conflict itself, but an attempt to understand the conflict from (neo)liberal, (neo)realist and critical theories. My conclusion is twofold, on the one hand I propose and argue that, just as (neo)liberalism and (neo)realism are ultimately 
based on a kind of epistemological and ontological eclecticism when planning actions in international politics, emancipatory critical theories should opt for a critical materialist eclecticism beyond idealistic exceptions- in order to overcome the theoretical-práxico fractionalism of social movements and subaltern states; On the other hand, I affirm that the failure of the US in Afghanistan and the advent of the Taliban was due, among other things -permanent insecurity, widespread corruption and malpractice by the occupying troops- to the ignorance of the cultural subjectivity of the Afghan population, which revolves around Islam and its irrationalist precepts.

\section{Introducción}

El Acuerdo de Doha ${ }^{1}$ firmado el 29 de febrero de 2020 entre el gobierno de Donald Trump y los Talibanes (Departamento de Estado, 2020), marcó la hoja de ruta para la retirada de Afganistán por parte de EEUU y de sus aliados de la OTAN. Dicha decisión tomada, unilateralmente, por el presidente republicano en el marco de sus campañas electorales, y luego ratificada por el presidente Joe Biden, ha generado un debate público sobre cuáles son las razones que impulsaron a ambos presidentes a salir de Afganistán. Inmediatamente después

1. Fundamentalmente en el Acuerdo se establecía la retirada de todas las tropas de la OTAN de Afganistán, una promesa de los talibanes de evitar que Al-Qaeda opere en áreas bajo control de los talibanes y conversaciones entre los talibanes y el gobierno afgano. Estados Unidos accedió a una reducción inicial de su nivel de fuerza de 13.000 a 8.600 en julio de 2020 , seguido de una retirada total dentro de los 14 meses si el Talibán mantiene sus compromisos. de la Toma de Kabul por los talibanes el 15 de agosto de 2021, algunos actores neoconservadores vinculados a la esfera del realismo político, como el propio G.W. Bush (2021) o el estadista Henry Kissinger (2021), han catalogado de "grave error estratégico" la renuncia de la clase política estadounidense a seguir manteniendo la ocupación del territorio que le dio cobijo a Osama Ben Laden. Otros actores internacionales del imaginario liberal, como el diplomático Josep Borrell (2021) o el economista Daron Acemoglu (2021), no han tardado en definir dicha retirada como un fracaso de occidente frente al yihadismo, reflexionando acerca de por qué EEUU no pudo conseguir el objetivo de construir un estado democrático en Afganistán. Joe Biden (2021) respondió indirectamente afirmando que, en realidad, este nunca fue un objetivo. ¿Por qué se mintió entonces a la opinión pública internacional? ¿Era la lucha contra el terrorismo el único objetivo de la ocupación? Bajo estas premisas, el interés de esta investigación radica en repensar las teorías de las relaciones internacionales desde un enfoque materialista ecléctico, relacionándolas con el problema geopolítico de Afganistán, sin pretender abarcar la totalidad del abanico teórico, y tratando de responder implícitamente a la pregunta de por qué EEUU fracasó en el supuesto empeño de establecer un estado democrático en dicho país. Un empeño ideado como solución táctica contra el terrorismo internacional, pero también como un mecanismo estratégico de generación de legitimidad o hegemonía mediante la propaganda por la defensa de los derechos humanos de la población femenina e infantil.

En la primera sección del trabajo indago en las distintas teorías liberales de las relaciones internacionales como son, la 
teoría idealista, la sociológica, la republicana, la institucional, la interdependiente y la estructural; y concluyo con el eclecticismo de Moravcsik. Aquí utilizo como fuente base un trabajo de Rafael Grasa (2015) bien documentado; La crisis de los veinte años de E. Carr (2004); y el libro de la periodista de guerra Mónica Bernabé (2012). Como complemento analizo ciertos textos de actores del mundo (neo) liberal como pueden ser Daron Acemoglu (2021) o el Internacional Crisis Group (2021). En la segunda sección analizo la evolución histórica de las teorías realistas de las relaciones internacionales, id est, el realismo ofensivo y defensivo. Para ello he examinado los capítulos de libro de Leire Moure (2015) y de Barbé y Soriano (2015), el libro sobre los Neoconservadores de Soriano y Mora (2006), incorporando al análisis textos de Robert Gilpin (1981) y Samuel Huntington (2001) así como de actores políticos actuales vinculados a esta gran corriente -Bush (2021); Kissinger (2021); Aznar (2021)- e implicados en el conflicto afgano. Los cuadernos de la Cárcel de Gramsci (1981), Imperio, y La multitud y la Guerra, de Hardt y Negri (2002, 2007) están presentes como parte de la caja de herramientas teóricas del propio autor. En la tercera sección estudio algunas teorías críticas o reflectivistas enfrentadas al mainstream realista y liberal, haciendo énfasis en los enfoques neogramsciano, habermasiano, feminista y poscolonial, teniendo como fuentes primordiales a Robert Cox $(1981,1983)$ y a José Antonio Sanahuja (2015, 2018). Como complemento cito la tesis doctoral de Hakami (2010) un refugiado afgano que nos permite romper, así sea someramente, con los enfoques occidentalistas. En la cuarta, finalizo con una breve reflexión, a manera de cierre, donde pongo en valor a un eclecticismo crítico materialista como enfoque holístico e inter seccional de las teorías críticas emancipatorias. También afirmo que el fracaso de EEUU en Afganistán y el advenimiento Talibán, fue debido, entre otras cosas, -inseguridad permanente, corrupción generalizada y malas prácticas de las tropas ocupantes-, al desconocimiento de la subjetividad cultural de la población afgana que gira en torno al islam y a sus preceptos irracionalistas.

\section{Interpretaciones desde las teorías liberales}

Como es sabido el liberalismo ha tenido el honor de haber puesto la piedra fundacional de la teoría de las relaciones internacionales. Tal como ocurrió también al finalizar la II Gran Guerra, -cuyos productos fueron la ONU y la Declaración Universal de los Derechos Humanos- el estado de ánimo de la opinión pública de los Estados involucrados en los meses finales de la I Guerra Mundial, era proclive a escuchar y a recibir de buen grado las ideas bien intencionadas de construcción de la paz "perpetua" por parte de la clase política. Las apetencias y necesidades imperialistas habían llevado a la sociedad mundial a la guerra y a la muerte. Se debía salir adelante e impulsar el desarrollo de las precarias fuerzas productivas. De entre todos los autores internacionalistas liberales de la época, a saber: J. A. Hobson, Norman Angell, Leonard Wolff, Arnold Toynbee, David Mitrany o Alfred Zimmern, destacó el presidente estadounidense Woodrow Wilson. Sus ideas, reflejadas en el programa de los Catorce Puntos $^{2}$ era que las relaciones internacio-

2. El 8 de enero de 1918, Wilson pronuncia ante el Congreso un discurso llamado "Nuestro pro- 
nales avanzan hacia una situación de mayor libertad, paz, prosperidad y progreso. (Salomón, 2002:5) Frente al análisis de la realidad "tal como es", se proyectaba la necesidad del "deber ser" kantiano en función de una concepción positiva de la naturaleza humana y del manejo de la razón, herencia de la llustración, como herramienta de perfeccionamiento social. Esta convicción podría materializarse si se promovía la cooperación internacional para avanzar en el objetivo de paz, bienestar, democracia y justicia. (Grasa, 2015: 102) El resultado de ello fue la Sociedad de Naciones ${ }^{3}$, los Tratados de Locarno ${ }^{4}$ y el Pacto Briand-Kellogg ${ }^{5}$. La base filosófi-

grama es la paz mundial", en el que propone 14 puntos para acabar con la Primera Guerra Mundial. El fin de la diplomacia secreta, la liberación del comercio, la reducción de armamentos militares, la autonomía de los pueblos del Imperio Otomano y Austrohúngaro y la creación de la Liga de Naciones son los elementos más importantes.

3. Esta organización internacional solucionaría de manera pacífica y democrática los posibles problemas surgidos entre las naciones, siempre mediante una negociación pública, es decir, evitando la llamada "diplomacia secreta". (Hobsbawm, 2003: 42)

4. Conjunto de acuerdos firmados en octubre de 1925 por los que Alemania, Francia, Bélgica, Gran Bretaña e Italia garantizaban el mantenimiento de la paz en Europa Occidental y el respeto a las fronteras a través de comités de arbitraje. El problema estuvo en el este ya que Stresemann como ministro de exteriores alemán no reconoció ninguna frontera dejando la puerta abierta a las acciones de Hitler.

5. Firmado en agosto de 1928 entre el secretario estadounidense Frank Billing Kellogg y el jefe de la diplomacia francesa Aristide Briand, ambos países se comprometían a garantizar una paz internacional duradera mediante la renuncia de la guerra como instrumento para resolver los conflictos de política exterior. Se decidió establecer un tribunal de arbitraje, auspiciado por la ca que estaba detrás de estos presupuestos es la tesis liberal de la armonía de intereses. El individuo, al perseguir su propio interés, persigue el de la comunidad, y al promover el interés de la comunidad, promueve el suyo propio. (Carr, 2004: 85) Este individuo actúa sin la intención de promover el interés público, sino que es conducido por una mano invisible a promover un fin que no formaba parte de su intención. Lo que era cierto para los individuos se presumía que también era cierto para las naciones, de tal manera que las naciones al servirse a sí mismas sirven a la humanidad. (Carr, 2004: 88) Esta idea, según Carr, explicaría por qué Wilson vio en la autodeterminación nacional la clave de la paz mundial. En esta línea, inspirada por la teoría de la armonía de intereses y tras la Primera Guerra Mundial, los liberales promocionaron la idea de que existía un interés mundial por la paz que era identificable con el interés de cada nación individual, ignorando la divergencia de intereses entre las naciones deseosas de mantener el statu quo y las naciones deseosas de cambiarlo. Edward Carr, considerado el gran fundador de la teoría de las relaciones internacionales y padre del realismo, en un debate indirecto con los idealistas, deconstruye este discurso liberal en vísperas de la Segunda Guerra Mundial. "En primer lugar, la historia es una secuencia de causa y efecto, cuyo transcurso puede ser analizado y comprendido mediante un esfuerzo intelectual, pero no -como creen los utópicos- dirigido por la imaginación. En segundo lugar, la teoría no crea -como suponen los utópicos- la práctica, sino la

Sociedad de Naciones, el cual debía decidir sobre todas las disputas entre los países. Pronto recibió la adhesión de las principales potencias del momento. 
práctica a la teoría [...] En tercer lugar, la política no es -como pretenden los utópicos- una función de la ética, sino la ética de la política [...] La moralidad es producto del poder." (Carr, 2004: 110) Al final de los años treinta la historia le daba la razón a Carr al estallar la Segunda Guerra Mundial.

A partir de la Segunda Guerra Mundial, el liberalismo, según la tipología que menciona Grasa (2015: 105), se va desarrollando en diferentes escuelas hasta la década de los noventa y la posterior refundación de Moravcsik. Estas escuelas pueden ser resumirse en cinco sub enfoques, id est:

1. Liberalismo sociológico: frente a las tesis realistas que reducen en general la esfera de las relaciones internacionales a las relaciones entre Estados-nación, el liberalismo sociológico hace énfasis en la importancia de las interacciones y cooperación entre personas, grupos y organizaciones más allá de las fronteras nacionales. Todo ello favorece el desarrollo de un mundo más pacífico. Karl Deutsch y James Rosenau serían autores importantes de esta corriente.

2. Liberalismo republicano: influenciado directamente por las obras de Kant, defiende la idea de que las democracias liberales son más pacíficas que otros sistemas políticos. Autores como Michael Doyle explican las condiciones de viabilidad para dicha paz: las normas democráticas de resolución pacífica de las controversias; los fundamentos morales compartidos; y la cooperación económica.

3. Liberalismo institucional: de influencia wilsoniana hace énfasis en el papel regulador de las instituciones internacionales como instrumentos de promo- ción de la cooperación entre Estados, al asegurar flujos regulares de información y por ende oportunidades para negociar. Estos flujos llevan al surgimiento de regímenes institucionales que pueden ser modificados o extinguidos si cambian las condiciones iniciales de surgimiento. Un autor importante de esta corriente es Robert Keohane.

4. Liberalismo de la interdependencia: en nuestra opinión, este sub enfoque constituye una síntesis derivada de los tres anteriores. Pone el acento en la dependencia mutua entre personas, pueblos y gobiernos en la esfera nacional e internacional de tal forma que las actuaciones de cada actor afectan a los restantes. De aquí saldrán dos nuevos sub enfoques: la teoría de la integración de David Mitrany; y la teoría de la interdependencia compleja de Robert Keohane y Joseph Nye. Esta última señala la importancia creciente de un poder suave, basado en la persuasión, para establecer las reglas del juego y los marcos de negociación.

5. Liberalismo estructural: estudia la viabilidad de generalizar los rasgos fundamentales de las democracias liberales al orden mundial en base a cinco condiciones, esto es, la creación de pautas de seguridad co-vinculantes; la existencia de una hegemonía receptiva; la presencia de otras grandes potencias parciales; la apertura económica; y la identidad cívica compartida. Deudney e Ikenberry son autores representativos.

A este escenario evolutivo habría que añadir la aportación de Andrew Moravcsik en su intento de reconstrucción del paradigma. Según Moravcsik, los liberales sostienen que la configuración de las 
preferencias del Estado, como productor de ideas e intereses, es el factor explicativo fundamental de la conducta en la política mundial y no las capacidades materiales -como señalan los realistas- ni la configuración de los regímenes institucionales -como afirman los neoliberales institucionalistas-. (Moravcsik, 1997, en Grasa, 2015: 113) De esta forma, Moravcsik expulsa a los institucionalistas del enfoque liberal que, por otra parte, habían ya manifestado su relativa sintonía con el neorrealismo estructural de Kenneth Waltz que veremos ut infra. Según Grasa, Moravcsik refunda el liberalismo a través de tres asunciones nucleares: la asunción de las demandas de los individuos como previas a la esfera política; la asunción del carácter representativo del Estado respecto de uno de los grupos o coaliciones sociales a lo interno de las fronteras nacionales; y la asunción de la variabilidad en la configuración del Estado en la esfera internacional en función de los cambios internos o interdependencia de las políticas públicas. (Grasa, 2015: 114-115) En definitiva, el liberalismo de Moravcsik parte de las variaciones en los fines para explicar los cambios, interrelacionando lo interior y lo internacional.

Con esta síntesis, un poco agria, tal vez podamos comprender mejor ciertos análisis y declaraciones de corte liberal realizadas por diferentes actores a colación de la retirada de EEUU de Afganistán. El economista Daron Acemoglu ${ }^{6}$, en un artículo publicado pocos días después de la toma de Kabul por los talibanes, explicó, a su criterio, por qué EEUU fracasó a la hora de construir un Estado moderno, centrali-

6. Autor de Por qué fracasan los países. Es profesor de economía del Instituto Tecnológico de Massachusetts y uno de los economistas más citados en el mundo. zado y democrático en Afganistán. EEUU, advierte Acemoglu, cometió el grave error de intentar construir un Estado centralizado de arriba hacia abajo con técnicos extranjeros sin establecer alianzas de cooperación con una sociedad civil profundamente heterogénea (Acemoglu, 2021: 2). Aquí se puede apreciar cierta influencia de los postulados del liberalismo sociológico, de la interdependencia y del propio Moravcsik respecto a la importancia de la sociedad civil a la hora de establecer relaciones con el Estado a lo interno y con los otros Estados a lo externo. Dicho esto, puede resultar paradójico que el presidente Biden negara en su discurso a la Nación que construir un Estado democrático en Afganistán fuera un objetivo de EEUU. "Nuestro único interés nacional vital en Afganistán sigue siendo hoy lo que siempre ha sido: prevenir un ataque terrorista en la patria estadounidense" (The White House, 2021) Desde este punto de vista no existiría ningún fracaso ni ninguna responsabilidad política de los gobiernos estadounidenses y, por lo tanto, tanto la intervención como la ocupación no habrían sido en balde. Josep Borrell, Alto Representante de la Política Exterior de la Unión Europea, le replica sin tapujos, "Io que ha ocurrido en Afganistán es una derrota del mundo occidental", y hay que "mirarlo de frente y tener el valor de reconocerlo y analizar las causas y sus consecuencias, que desde el punto de vista geopolítico serán muy importantes". (RNE, 2021) Lo que se percibe aquí es una cierta ruptura de la estrategia atlántica por parte de la Unión Europea al darse cuenta Borrell que EEUU está renunciando a su papel de policía imperial -en términos negristas- y de líder de la globalización como proyecto liberal. Es tanto así que el propio Borrell ha declarado que quizás sea el momento de pensar 
en la necesidad de crear un ejército unificado de la Unión Europea que obedezca exclusivamente a las directrices políticas propias. Por ende ¿qué le está ocurriendo al hegemón del capitalismo global? Parece obvio que EEUU, desde el 2003, con la guerra unilateral en Irak, no ha hecho más que ir perdiendo credibilidad y por tanto hegemonía ante la opinión pública global. A la guerra de Irak, le sucedió el Crash de 2008, el bloqueo de la Organización Mundial del Comercio, la guerra comercial con China y la pandemia de la Covid 19. Cada uno de estos hechos implica un golpe moral al utopismo liberal que preconizaba la globalización de la democracia y el libre comercio tras la caída de la Unión Soviética. La realidad es que la retirada de Afganistán supone el abandono de la población afgana a su suerte y más en concreto la renuncia a la defensa de los derechos individuales de las mujeres y niños. He aquí, quizás, el porqué de la decepción del Alto Representante de la Unión Europea. ¿Cuántos soldados de la OTAN han muerto en Afganistán? Según el Instituto Watson de la Universidad de Brown, murieron 1.144 soldados aliados frente a 2.324 de EEUU. De esos 1.144, España puso 102. Además, fallecieron 46.319 civiles afganos, de los cuales más de 10.000 fueron a manos de las tropas de la OTAN. (Watson Institute, 2021) A esto se suma el drama humanitario. Debido a la escasa aportación económica internacional, en este momento no hay dinero para pagar los salarios ni para comprar alimentos, medicinas o agua potable. La vida de un millón de niños está en juego ya que se prevén muertes por desnutrición inminentes. (ACNUR, 2021) $Y$ entonces ¿para qué se sacrificaron tantos muertos y recursos? Mónica Bernabé, una periodista de investigación española que ha trabajado en Afganistán entre
2006 y 2014, aporta, en su libro sobre Afganistán, datos concisos que desnudan los discursos oficiales de los altos mandos militares y de los distintos actores sobre el terreno, así como los "buenos deseos" de los representantes de los países implicados. Permítannos abusar un poco de su fuente, merece la pena.

En la conferencia de Londres celebrada en enero de 2006 una cincuentena de países aprobó el Afghanistan Compact -Pacto para Afganistán- donde se establecía las metas a alcanzar en cinco años en materia de seguridad, gobernabilidad, justicia, derechos humanos, economía y desarrollo social. Ninguno de los objetivos se cumplió, pero los diferentes actores sobre el terreno fingían lo contrario en sus declaraciones rutinarias. Mientras tanto, los hechos que ocurrían en el día a día entre los militares desplegados y los civiles afganos fueron mermando la legitimidad de los ocupantes y preparando lentamente las condiciones para la reconquista del poder por parte de los talibanes. El 29 de mayo de 2006, un vehículo militar de EEUU que circulaba por el noroeste de Kabul perdió el control y se chocó contra un coche de civiles muriendo varios de ellos. Tras el incidente, decenas de afganos empezaron a lanzar piedras contra los soldados que respondieron abriendo fuego. A partir de ahí, relata Bernabé, se desató una protesta espontánea contra todo lo que oliera a extranjero. Saquearon decenas de comercio, quemaron coches y puestos de vigilancia de las Naciones Unidas y asaltaron la sede de diversas ONG internacionales. (Bernabé, 2012: 164) Los afganos habían dejado de ver a los extranjeros como salvadores. Estos incidentes habían ocurrido días después de que fuerzas estadounidenses bombardearan una localidad en la provincia 
de Kandahar, en el sur del país, y se registraran decenas de víctimas civiles. En agosto de 2007, ante la sede en Kabul de la UNAMA ${ }^{7}$ decenas de mujeres afganas se manifestaron para reclamar que la comunidad internacional pusiera fin a la situación de impunidad generalizada en el país y se ajusticiara a los señores de la guerra por los crímenes cometidos durante los últimos 20 años. En el año 2003 el gobierno afgano había ratificado el Estatuto de Roma, según el cual la Corte Penal Internacional podría actuar en Afganistán, pero solo en crímenes cometidos a partir de la firma del tratado, es decir, a partir del 2003. En consecuencia, todos los señores de la guerra que formaban parte del gobierno y del Parlamento conseguían la inmunidad total. Según Bernabé, tres años más tarde, la asociación Human Rights Watch hizo público un informe sobre las atrocidades cometidas por los muyaidines ${ }^{8}$ durante los años 1992 y 1993. Algunos de los líderes muyaidines ocupaban cargos de poder en el gobierno o el Parlamento. La respuesta fue la promulgación en 2007 de una ley de amnistía a iniciativa de los diputados del Parlamento: "Todas las facciones y partidos políticos que participaron en las hostilidades de una manera u otra antes de la administración interina serán incluidos en un programa de amnistía general". (Bernabé, 2012: 190-192-193)

Por consiguiente, parece ser que las prácticas de las tropas extranjeras, el comportamiento de las instituciones afganas y de la propia comunidad internacional, -que gestionaron el proceso de creación de instituciones-, fueron generando un

7. Misión de asistencia de las Naciones Unidas en Afganistán.

8. Según la RAE, combatiente islámico fundamentalista. progresivo rechazo en la población civil y la aceptación tácita de los talibanes como agentes de orden para desgracia de las mujeres. Durante la etapa talibán las mujeres habían retrocedido décadas en derechos. Durante los años de ocupación extranjera se tenía la oportunidad de recobrarlos e incluso de superar los adquiridos durante la época soviética a través de la inversión en educación y desarrollo, pero por desgracia no fue así. En vez de eso, seguían muriendo civiles por la acción de los bombardeos aéreos de las tropas internacionales. Según datos de la UNAMA mencionados por Bernabé, en 2008 perdieron la vida 552 civiles. Los soldados extranjeros solían requerir apoyo aéreo, es decir, la intervención de helicópteros de combate cuando eran atacados sobre el terreno. El problema era que muchas veces esos helicópteros abrían fuego en zonas donde había población civil, como ocurrió en la provincia de Badguis, centro-oeste de Afganistán el 5 de noviembre de 2008. En dicha provincia estaban desplegadas las tropas españolas y fueron auxiliadas por helicópteros estadounidenses e italianos, los cuales bombardearon la zona durante cuatro horas. Murieron 21 personas. Los que sobrevivieron viajaron a Kabul para quejarse al presidente afgano: "Nosotros estamos del lado del gobierno, pero si algo así vuelve a ocurrir, no respondemos de nuestros actos y apoyaremos a la insurgencia". (Bernabé, 2012: 255)

En Afganistán, existía un desorden de fuerzas extranjeras, un totum revolutum. Había dos mandos militares, el de la Operación Libertad Duradera liderada por Estados Unidos, y el de la Fuerza Internacional de Asistencia para la Seguridad en Afganistán (ISAF), que dirigía la OTAN. La Operación de Libertad Duradera llevaba 
a cabo operaciones antiterroristas, pero también contaba con el llamado Mando de Transición de Seguridad Combinada que se dedicaba a la formación de la policía y el ejército afganos. La ISAF se encargaba de los denominados PRT (Equipos de Reconstrucción Provincial), que operaban bajo órdenes de cinco mandos regionales: norte, sur, este, oeste y zona centro. Por otra parte, la Unión Europea disponía de una misión policial conocida con las siglas EUPOL. A ello había que sumar el centro de detención de Bagram, al norte de Kabul, dirigido por EEUU para recluir a los sospechosos de haber cometido actos terroristas. Luego de interrogarlos podían ser trasladados a Guantánamo. Como señala Bernabé, las interrogaciones no cumplían las normas internacionales de guerra establecidas en las convenciones de Ginebra por orden expresa del presidente Bush en febrero de 2002. La consecuencia fueron las torturas, tal como salió a la luz en la prensa estadounidense en 2004 con motivo de los interrogatorios en la cárcel de Abu Ghraib en Irak. En Afganistán, las torturas no fueron publicadas, pero el New York Times se hizo eco el 20 de mayo de 2005 del caso de un joven taxista que murió en Bagram torturado -le destrozaron los muslos- sin haber cometido ningún delito. (Bernabé, 2012: 257)

Estos hechos iban inflando la indignación de la población afgana. Pero la lista suma y sigue. El director ejecutivo de la UNODC ${ }^{9}$, Antonio María Costa, denunció la pasividad internacional ante el narcotráfico en un informe de 2007 titulado Afghanistan Opium Survey. Costa afirmaba que existía una aceptación tácita del tráfico de opio por parte de las tropas internacionales como una forma de conseguir informa-

9. Oficina de las Naciones Unidas contra la droga y el delito ción de inteligencia en operaciones contra Ios talibanes y Al Qaeda. (Bernabé, 2012: 270) En el terreno militar puede verificarse mejor cómo la situación se escapaba de las manos. En 2007, los canadienses desplegados en Kandahar, el bastión talibán, al sur, advertían de que ellos solos no podían controlar la zona con sus 2.750 efectivos y pidieron ayuda a los otros países de la OTAN. EEUU se encontraba combatiendo al este, en la frontera con Pakistán. El Reino Unido se encargaba de Helmand, limítrofe con Kandahar. Holanda y Australia se ubicaban en Uruzgán, también en el sur. Alemania tenía sus soldados en Kunduz, Balkh y Badakhashán, al norte. El resto de los países con tropas en Afganistán hicieron también oídos sordos a las peticiones de ayuda de los canadienses, incluidos las tropas españolas. Ante la situación, el comandante en jefe de la ISAF, el general Dan McNeill, mostró su malestar espetando que se encontraba a merced de las reglas nacionales. (Bernabé, 2012: 276)

Barack Obama, uno de los presidentes que quizás mejor simboliza los ideales del liberalismo wilsoniano y kantiano, anunció en un discurso televisado en marzo de 2009 su nueva estrategia para Afganistán. Aumentaría el número de soldados con 21.000 nuevos efectivos. Estos efectivos formarían parte de la ISAF y se desplegarían exclusivamente en las provincias de Kandahar y Helmand, en el sur, donde los canadienses pedían refuerzos desde hacía más de un año. Además, incrementaría su esfuerzo en desarrollo, enviando expertos en agricultura, educadores, ingenieros y abogados. Parecía que Obama había comprendido la situación. Para coordinar la nueva estrategia nombró al general Stanley McChrystal jefe de las tropas internacionales. McChrystal en su in- 
forme al secretario de defensa, Robert Gates, echaba por tierra todo lo que habían hecho las tropas internacionales y abogaba por un cambio radical. Creía necesario aumentar las tropas, pero sobre todo consideraba más importante ganar empatía con la población afgana. Se quejaba de que los soldados no supieran lengua local y que no tuvieran ni idea de la cultura afgana. "Las tropas de la ISAF tienen que dedicar el máximo tiempo posible a estar con la gente y el mínimo a estar dentro de los coches blindados o detrás de los muros protegidos de las bases militares". (Bernabé, 2012: 293) También opinaba que las fuerzas internacionales debían poner freno a la corrupción y al abuso de poder del gobierno afgano porque eso hacía que la población no confiara en las instituciones ni tampoco en las fuerzas internacionales al considerarlas cómplices. Nada más lejos de la realidad. El 20 de agosto de 2009 se celebraron elecciones presidenciales y Hamid Karzai ganó de nuevo en medio de protestas por fraude. La Misión de Observación Electoral de la Unión Europea denunció que el día de las elecciones se llenaron urnas a gran escala con votos fraudulentos. En total 1,5 millones de votos. El número dos de las Naciones Unidas en Afganistán, Peter Galbraith, acusó a su superior, el noruego Kai Eide, de haber ordenado ocultar pruebas sobre el fraude electoral. Galbraith fue destituido. A pesar de este escándalo Barack Obama declaró que las votaciones habían sido un éxito. ¿Cómo afectaba esto a la opinión pública afgana sobre la democracia? El centro AREU ${ }^{10}$, llevó a cabo un estudio sobre la percepción de la población afgana acerca de la democracia. La mayoría de los entrevistados identificaban la democracia con inmoralidad y con

10. Afghanistan Research and Evaluation Unit. disponer de libertad absoluta para hacer lo que se quisiera. (Bernabé, 2012: 322)

Con estos datos sobre la mesa no es de extrañar que la población afgana percibiera el ideario democrático de las tropas y de los países de las OTAN, empezando por el gobierno de EEUU, como una ficción utópica parafraseando a Edward Carr (2004) en su crítica al voluntarismo liberal del presidente Wilson en el período de entreguerras. El mito democrático se desplomaba y con él la legitimidad de la ocupación. Había que iniciar conversaciones con los talibanes y salir corriendo. Las conversaciones comenzaron en 2010 y los países de la OTAN aprobaron la retirada de sus efectivos para 2014, una vez hubieran traspasado la responsabilidad del conflicto al gobierno de Karzai. Empero, de inmediato fue evidente que no estaban preparados para defender al país y las tropas finalmente se quedaron hasta que en febrero de 2020 se firmó el Acuerdo de Doha a partir del cual se pactaba una salida sin apenas contraprestaciones por parte talibán. Era una rendición en cubierta.

Estos datos arrojados por nuestra periodista de guerra coinciden en cierto grado, mutatis mutandis, -Mónica es más crítica- con las conclusiones de algunos especialistas internacionalistas del ámbito del liberalismo institucional o neoliberalismo, como el realizado por Laurel Miller ${ }^{11}$ del Internacional Crisis Group ${ }^{12}$. Miller

11. Analista del think tank Internacional Crisis Group desde 2019, dirige el programa de Asia. Ha sido representante adjunta del departamento de Estado de EEUU para Afganistán y Pakistán.

12. Organización no gubernamental, "independiente", sin fines de lucro basada en Ginebra y con presencia mundial. La ICG está enfocada a la resolución y prevención de conflictos armados internacionales, para lo cual combina el trabajo 
(2021) en una audiencia reciente ante el Comité de Relaciones Exteriores del Senado de EEUU, expuso las que, a su juicio, son las cinco lecciones aprendidas durante estos 20 años de ocupación, a saber: 1) Hay que ser muy cautelosos a la hora de tratar de cambiar un régimen político; 2) Si el éxito de tu estrategia depende de circunstancias particulares, asegúrese de controlar esas condiciones; 3) Reconozca lo mucho que no sabe, pero también acepte lo que sabe y cambie su política en consecuencia; 4) La condicionalidad de la ayuda no funciona si su estrategia depende del éxito del beneficiario; y 5) Reconocer los límites de la capacidad de Estados Unidos para imponer su voluntad cuando no es vital desde el punto de vista existencial. (Miller, 2021: 3-14) En definitiva, Miller aboga por el sentido común neoliberal institucional en la acción exterior priorizando la negociación frente a la fuerza bruta.

\section{Interpretaciones desde las teorías realistas}

Los realistas, desde que la disciplina de las Relaciones Internacionales vio la luz al comienzo del período de entreguerras a manos del liberalismo wilsoniano, han tratado de describir y explicar el mundo "tal como es" y no cómo debería ser. El medio internacional constituye para ellos un entorno peligroso e inseguro carac-

de especialistas en el terreno y las labores de sensibilización desde sus oficinas regionales. Recibe soporte económico de varias instituciones gubernamentales de países europeos y de Australia, Canadá, Turquía y EE. UU. También recibe fondos de instituciones internacionales, organizaciones no gubernamentales y fundaciones privadas. Y en su llamado Concejo de Asesoría se encuentran empresas multinacionales. terizado por el conflicto, la anarquía y la competición entre Estados soberanos y ante la ausencia de un gobierno global. (Moure, 2015: 62) De esta manera, la característica fundamental de la política internacional será la lucha por el poder en un entorno anárquico por lo que las preferencias ideológicas resultarán accesorias en el plano internacional (Morgenthau, 1948, citado en Moure, 2015: 69), a pesar de que se venda la idea contraria a las opiniones públicas de los Estados con el objeto de legitimar las acciones.

A partir de aquí el realismo se ha dividido en dos grandes campos: el realismo defensivo y el ofensivo heredero de Morgenthau. El realismo defensivo fue introducido por J.H. Herz en el contexto de los desarrollos nucleares y de la bipolaridad del poder en la Guerra fría, que reemplazó al viejo sistema multipolar de equilibrio. En este escenario nuclear, la búsqueda de recursos de poder de forma ofensiva como abogaba Morgenthau tendría poco sentido y la necesidad de lograr seguridad pasaría a constituir la principal preocupación del Estado. Para Herz, la inseguridad es un efecto consustancial a la anarquía. Por ello, las unidades han de afrontar los efectos del llamado dilema de la seguridad. El dilema consiste en que la incertidumbre impulsa a los Estados a lograr mayores cotas de poder como medio para mejorar su situación de seguridad. (Herz, 1959, citado en Moure, 2015: 7172) Otra versión del realismo defensivo en el contexto de la Guerra Fría es la del neorrealista K. Waltz, que afirmaba que el principal interés de los actores, los Estados-Nación, es mantener su posición dentro del sistema anárquico, por tanto, la maximización de su poder pasaría a ser una cuestión secundaria. Siguiendo a la lógica del mercado, concluye que el siste- 
ma político internacional nace de la actividad de entidades egoístas cuyos objetivos no están en crear un orden sino en satisfacer sus propios intereses. La estructura internacional emerge de la coexistencia de un número pequeño de Estados potentes. (Waltz, 1979, citado en Moure, 2015: 76) Entre fines de los 70 y principios de los 80, esta corriente neorrealista -realismo estructural- confluirá con la escuela neoliberal -liberalismo institucional- de Robert Keohane. Se trata del debate neoneo, o Cuarto Debate que llevará a una síntesis y aceptación mutua como teorías complementarias para mantener el statu quo en el orden mundial. Según Barbé y Soriano (2015: 137) este debate condujo a un nuevo discurso dominante en las Relaciones Internacionales en base a cuatro elementos: el abandono de los transnacionalistas de la construcción de un paradigma que sustituyese al realismo; a la convergencia entre neoliberales y neorrealistas sobre la definición y el estudio de los regímenes internacionales; la deslegitimación académica de las aproximaciones reflectivistas o críticas; y la incorporación de variables constructivistas. En términos prácticos, el neorrealismo en general asume que, debido a la anarquía del sistema internacional, los Estados tienen que centrar sus preocupaciones en las cuestiones de seguridad y en los conflictos armados, mientras que el neoliberalismo institucional se concentra en las cuestiones de economía política internacional. De igual modo, mientras que el neorrealismo se enfoca en las capacidades antes que en las intenciones, el neoliberalismo presta más atención a las intenciones frente a las capacidades. (Barbé y Soriano: 149).

A primera vista, la teoría del dilema de seguridad de Herz, en el contexto de la lucha contra el terrorismo como nuevo enemigo a combatir tras el fin de la Guerra Fría, pudiera haber tenido bastante influencia entre los neoconservadores republicanos luego de los atentados del 11 de septiembre del 2001. De esta forma "entramos en Afganistán en medio de un amplio apoyo público en respuesta al ataque de Al Qaeda". (Kissinger, 2021: 3) Es decir, la intervención, tras activar por primera vez en la historia el artículo 5 de la OTAN ${ }^{13}$, fue un producto en legítima defensa que además serviría para "controlar" a los terroristas en pro de la seguridad del territorio norteamericano. Empero, como sabemos, la red terrorista de Al Qaeda no se circunscribía al Estado Talibán por lo que la intervención en legítima defensa, apoyada por el Consejo de Seguridad de la ONU ${ }^{14}$ y regulada en el artículo 51 de la Carta de Naciones Unidas, se convirtió en pocos meses en una estrategia ofensiva global, sin respaldo del Consejo de Seguridad, a partir del nuevo concepto de "Guerra Preventiva". Aquí recobra sentido revisar las propuestas de dos teóricos del realismo ofensivo que nos permiten comprender el trasfondo ideológico de la estrategia neocon, id est: Robert Gilpin y Samuel Huntington.

Gilpin (1981) plantea su teoría de la estabilidad hegemónica en contraposición al realismo estructural de Waltz basado en los equilibrios de poder entre unas pocas potencias. Frente a la idea de maximización de la seguridad, Gilpin presenta las relaciones internacionales como una lucha permanente por la riqueza y el poder donde la hegemonía, y no la anarquía, será el principio ordenador del sistema. De tal forma que la estabilidad del orden mundial dependerá del grado de satisfac-

13. Estipula que un ataque a uno de los miembros será considerado un ataque a todos los miembros.

14. En su resolución 1368 y 1373 de 2001. 
ción de las grandes potencias con el statu quo promovido por la potencia hegemónica. Para ello el prestigio del hegemón será clave. Un prestigio entendido como legitimidad, al estilo gramsciano, pero con una diferencia fundamental, Gilpin hace recaer el peso de las facultades del centauro maquiaveliano ${ }^{15}$ en la superioridad económica y militar del hegemón, es decir, en la fuerza, mientras que Gramsci (1981) y los neogramscianos de la Teoría Crítica ponen el acento en el consenso y en la persuasión como estrategia cultural de largo aliento para cualquier tipo de alianza de poder o contrapoder. En nuestra opinión, esta tesis de la estabilidad hegemónica encaja muy bien con la estrategia ofensiva e imperialista de la administración de G. W. Bush, sin argumentos en Irak -a pesar de la paradoja de que Gilpin se opusiera a la invasión-, que rompe además con la tendencia consensual reinante entre las potencias durante la década de los noventa al fragor de la continuación de la ola democratizadora ${ }^{16}$, del Fin de la Historia ${ }^{17}$ y de la gobernanza imperial de la globalización ${ }^{18}$. A decir de

15. El centauro Quirón, citado por Maquiavelo en el Príncipe, mitad hombre y mitad bestia, enseñaba a los gobernantes de la antigüedad, según los poetas alegóricos, que hay dos modos de defenderse y de gobernar, a saber: con las leyes y por la fuerza. Cuando las leyes no son suficientes hay que saber utilizar la fuerza.

16. A propuesta de Samuel Huntington se inició a mediados de los setenta hasta la década de los noventa en diferentes continentes.

17. Fukuyama, de acuerdo con Huntington, añadía que dicha tercera ola, tras la caída del socialismo "real" sería definitiva en favor de la democracia liberal. Esta democracia liberal se globalizaría sin imposición. La paradoja está en que Fukuyama apoyaría la invasión de Irak aunque más tarde se retractaría.

18. Según Toni Negri, esta globalización neoliberal que se intensifica exponencialmente tras la
Negri y Hardt (2007) la invasión en Irak fue un intento del hegemón como monarca imperial, de un golpe de Estado fallido, -el 18 de Brumario de G. W. Bush-, contra la aristocracia global al prescindir de los procedimientos persuasivos, institucionales y consensuales en pro de una gestión unilateral de la gobernanza.

El otro autor realista mencionado ut supra, en su variante cultural, que alienta indirectamente, a nuestro entender, una estrategia ofensiva y que justificaría en algún grado la estrategia neoconservadora, es Samuel Huntington. En respuesta al Fin de la Historia de Fukuyama, Huntington (2001, [1993]) afirma que tras la caída de la Unión Soviética los conflictos dejarán de ser ideológicos, en sentido de proyectos político-sociales, para enfrentar a las distintas civilizaciones entre sí, por lo que la democracia liberal solo hallaría terreno fértil dentro del mundo occidental. Dicho enfrentamiento se explicaría por las grandes diferencias culturales y en valores de las distintas civilizaciones. Las sociedades islámicas serían rivales de la occidental por antonomasia. Más allá de las críticas acertadas contra esta teoría ${ }^{19}$, Huntington influyó en diferentes estratos de la clase política occidental, incluyendo

caída del bloque soviético es gestionada de forma consensual por un gobierno global informal constituido por las potencias del G7 más Rusia junto a las grandes corporaciones transnacionales a través de instituciones como el Foro Mundial de Davos.

19. Véase la crítica de Edward Said en el artículo El Choque de las Ignorancias de 2001 donde pone en duda la validez heurística del trabajo de Huntington que a través de la formulación de etiquetas ideológicas se pone al servicio de la clase dominante norteamericana para justificar precisamente cualquier tipo de intervención militar bajo el argumento de garantizar la "seguridad nacional" frente al carácter ofensivo del Otro. 
a los neoconservadores republicanos estadounidenses.

Una vez realizado este recorrido teórico sobre los enfoques realistas podemos analizar algunas posiciones de actores políticos pertenecientes a esta corriente, aún hoy mainstream junto al liberalismo institucional o neoliberalismo, respecto a la pregunta de por qué fracasó EEUU en Afganistán. En un artículo del 7/9/2021, ya referenciado, el incombustible Henry Kissinger no dudó en tratar de responder a la misma afirmando que el gobierno de G.W. Bush se equivocó al tratar de transformar a Afganistán en un Estado moderno con instituciones democráticas porque va en contra de la esencia geográfica y etnorreligiosa del país. Este análisis coincide con la tesis del Choque de Civilizaciones de Huntington consistente en rechazar la idea liberal de Fukuyama de llevar la democracia a culturas muy disímiles. Obviamente la diferencia con los teóricos liberales radica en que los neoconservadores de la administración Bush quisieron imponer la democracia a la fuerza con el argumento de que sería la única forma de evitar el restablecimiento de bases terroristas. Empero, los neoconservadores, incluyendo por extensión al ex presidente José María Aznar, no reconocen el fracaso de estos 20 años de ocupación e inversión de 2 billones de dólares destinados a dicha tarea. Simplemente culpan a la administración de Trump y Biden por la retirada. Las declaraciones de G.W. Bush dirigidas a las tropas el día posterior a la toma de Kabul se orientan exclusivamente a elevarles la moral sin autocrítica alguna: "El sacrificio no fue en vano. Ustedes mantuvieron a EEUU a salvo de nuevos ataques terroristas, proporcionó dos décadas de seguridad". (Independent, 2021) Kissinger, no obstante, sí lanza sus dardos contra Biden cuando advierte que EEUU no puede eludir ser un componente clave del orden mundial por sus capacidades y valores históricos. No puede evitarlo retirándose porque el terrorismo seguirá siendo un reto global. "La temeridad estadounidense agravaría la decepción entre los aliados, alentaría a los adversarios y sembraría la confusión entre los observadores". (Kissinger, 2021: 8)

¿Qué espeta el neoconservador Jose María Aznar? "En Afganistán se ha cometido un enorme error que vamos a pagar" "Esa guerra se ganó y de pronto, al cabo de un tiempo, quien gana la guerra decide rendirse y hacerlo de la manera más humillante posible. Eso tendrá unas consecuencias muy negativas para el mundo" (Aznar, 2021: 12) Al igual que Kissinger, Aznar se lamenta por el repliegue estratégico que supone la retira de Afganistán. Un repliegue ante el mundo que ya había iniciado el propio Trump. La pregunta es ¿por qué Trump y luego Biden deciden dicho repliegue? Esa pregunta no es respondida por ninguno de los actores en escena. Sería bueno recordar una cuestión mencionada por Gilpin (1981) y que estos actores realistas parecen estar olvidando. La base epistemológica de Gilpin para desarrollar su teoría de la estabilidad hegemónica no es otra que la lógica de la maximización de la utilidad marginal por parte de los Estados. Esto significa que cuando un Estado decide actuar en el escenario que sea y bajo la modalidad que sea, el beneficio extraído o retornado debe superar los costos invertidos en dicha actuación. Ya sabemos que para el realismo en general, incluyendo el neorrealismo hegemónico, esto significa el deber de obtener o de generar ganancias materiales directas o indirectas, es decir, a través del posicionamiento geoestra- 
tégico en el territorio que las produzcan a medio o largo plazo. En este orden de ideas habría que preguntarse qué beneficios ha obtenido EEUU tras la ocupación de Afganistán durante 20 años. He aquí el quid de la cuestión. Parece una obviedad que EEUU ha perdido mucha credibilidad y ha ganado poco desde el punto de vista material, más allá del desarrollo -que no se puede obviar- de las fuerzas productivas en el ámbito militar. En resumen, si tuviéramos que buscar las influencias recibidas de la realpolitik respecto de los teóricos realistas de las relaciones internacionales, se podría concluir que los decisores políticos conservadores toman elementos tanto de unos como de otros en una suerte de eclecticismo realista en pro del pragmatismo tal como ocurre también con los liberales respecto de sus teóricos. Es más, es tal la confluencia entre neorrealistas y liberales institucionales que el eclecticismo también se da de forma cruzada, en sintonía ya desde el Cuarto Debate en los 80, entre ambas familias epistemológicas por la sencilla razón de que ambas defienden el statu quo en el orden internacional.

El mejor ejemplo de este eclecticismo son los neoconservadores y la propia administración Bush. Ramón Soriano y Jesús Mora (2006), en su proyecto de investigación post Guerra de Irak, analizaron profusamente, junto a su equipo de trabajo, esta corriente ecléctica que fusiona elementos pragmáticos realistas con filosóficos liberales de índole kantiana junto a elementos straussianos. Así los neoconservadores políticos toman de Leo Strauss y de sus discípulos la idea fundamentalista de los valores absolutos frente al relativismo liberal. (Soriano y Mora, 2006: 59) Paradójicamente estos valores universales son, para los neoconservadores, la libertad y la democracia, que no pueden ser discutidos por su certeza natural e irracional. Valores que provienen en este caso, no de Strauss que aboga por un sistema elitista aristocrático al estilo platónico, sino de los Padres Fundadores de EEUU como tercer pilar epistemológico a tener en cuenta. Una vinculación problemática porque los Padres Fundadores no abogaban por el intervencionismo externo sino por relaciones de amistad entre naciones. En este sentido, John Quincy Adams sostenía que: "América no debe ir fuera en busca de un monstruo que destruir. Ella es campeona y vindicadora solamente de sí misma. Ella atenderá a una causa general mediante la fuerza de su voz y la benigna simpatía de su ejemplo". (Soriano y Mora, 2006: 82). De cualquier forma, en mi opinión, la vinculación de los neoconservadores con los Padres Fundadores no por ello deja de tener algunos elementos justificativos pues si bien es cierto que abogaban por las relaciones amistosas entre naciones, en el marco de su auto aislamiento temporal, no es menos cierto que desarrollaron un intervencionismo interno frente a los pueblos originarios, los cuales, y obviamente, veían a aquellos como externos. De hecho, esta expansión inclusiva de los Padres Fundadores respecto de los nativos tiene en común con los neoconservadores una idea de Imperio a la romana al buscar estos últimos la democratización "a toda costa" de los pueblos bárbaros, léase el mundo musulmán o los regímenes autoritarios y su inclusión en la órbita cultural occidental. De ahí que el proyecto constitucional estadounidense se base en ciertos aspectos en el sistema antiguo romano por intermedio de Maquiavelo. (Molina, 2018: 261-264) La otra influencia de los neoconservadores está en la obra de Inmanuel Kant. Los conceptos de Paz Perpetua e Imperativo Moral son traducidos al estilo ahistórico y abso- 
lutista de Strauss y reformulados en Paz Democrática e Imperativo Democrático. Empero, como Soriano y Mora (2006: 54) advierten, si para Kant el Imperativo Moral era una cuestión autónoma y subjetiva de la conciencia del individuo para los neoconservadores el Imperativo Democrático se convierte en razón de Estado y justificación para el intervencionismo ya que, según Kant, solo puede existir paz entre repúblicas en sentido liberal. En síntesis, los neoconservadores toman elementos de los realistas, -iquién puede negar la influencia del Choque de Civilizaciones de Huntington, o de la Teoría de la Estabilidad Hegemónica de Gilpin?-, de Kant, de Leo Strauss y del liberalismo de los Padres Fundadores. Como resultado de ello los neoconservadores devienen en una corriente ecléctica donde se combina el realismo ofensivo con el ideario liberal, eso sí, bastante deformado, en una suerte de "imperialismo democrático".

\section{Interpretaciones desde las teorías críticas o reflectivistas}

Contra las escuelas teóricas realistas, liberales y neoconservadoras que dominan las prácticas de la política internacional a través del quehacer de los gobiernos, con sus vaivenes, preferencias y modificaciones "ideológicas" (Moravscik, 1997), han surgido desde los años ochenta hasta la actualidad una serie de teorías críticas o reflectivistas (Keohane, 1988), que dieron inicio al llamado cuarto debate de las relaciones internacionales como discusión paralela a la Neoliberal-Neorrealista. Un debate que se podría decir, a motu proprio, nunca finalizó, sino que se ha alargado y enriquecido al incorporarse nuevos enfoques críticos que siguen producien- do a día de hoy teoría en contestación a dichas corrientes mainstream. A decir de Sanahuja (2018) estas teorías reflectivistas se diferencian del realismo y del liberalismo en que mientras estos enfoques dominantes, -ya hemos visto que Moravscik reconoce esos fallos-tratan de explicar la realidad internacional desde fuera de las relaciones sociales que la constituyen, las teorías críticas, lato sensu, interpretan la realidad desde ella misma en una suerte de doble hermenéutica. Esto significa que, si "los seres humanos interpretan el mundo a través de su reflexión, de sus prácticas, y de sus relaciones sociales; las Ciencias Sociales han de interpretar, a su vez, esas interpretaciones" (Sanahuja, 2018: 109) Por ende, mientras que las teorías explicativas de corte positivista pretenden proporcionar un explanans con fundamentación empírica de la sociedad internacional, para las reflectivistas o críticas, la teoría es parte de esa realidad social, histórica y contingente que debe ser explicada. Este explanandum es clave para la deconstrucción de los discursos de los diferentes actores implicados como un primer objetivo de análisis de las teorías críticas. Vinculado a este método deconstructivo, las teorías críticas están caracterizadas por un eje praxeológico definido por la posibilidad de la acción colectiva como agente del cambio en el orden mundial. Un cambio que dependiendo de a qué escuela reflectivista nos refiramos, tendrá una connotación heurística y proyectual distinta. Consiguientemente, se pudiera aseverar que existe un quinto debate interno entre los diferentes enfoques de la familia reflectivista donde se disputa la hegemonía de la epistemología crítica en relaciones internacionales.

Dejando al constructivismo y al postestructuralismo fuera de este quinto debate 
no declarado, al rechazar la posibilidad y deseabilidad de los cambios en la sociedad internacional vía acción colectiva, mencionaremos otros enfoques que consideramos más referenciales. Strictu sensu, bajo la denominación de Teoría Crítica se sitúan dos perspectivas distintas y -a nuestro criterio- hasta cierto punto complementarias, a saber, el enfoque neogramsciano y la Escuela de Francfort. Según Sanahuja (2015: 158), aunque el origen de la teoría crítica se encuentra en el proyecto emancipador de la modernidad y en la tradición intelectual de la ilustración que vincula crítica, razón y emancipación del ser humano a través de autores como Kant, Hegel y Marx; esta tradición se reactualizaría a lo largo del siglo XX con la irrupción de la Escuela de Francfort y con los aportes de Gramsci, de forma paralela y separada, en contraposición tanto a la visión liberal de la modernidad como a la del marxismo dogmático que habría negado la autonomía y la libertad a la que aspira, paradójicamente, ese proyecto emancipador. Así, la obra de Max Horkheimer Teoría tradicional y teoría crítica tiene carácter fundacional. Empero, no será hasta los años ochenta que la teoría crítica aparezca en los debates de las relaciones internacionales mediante los aportes neogramscianos de Robert Cox. Cox (1981) realizó la distinción entre las teorías que solventan los problemas o desajustes del orden social mundial dominante (problema-solving theory) y las que son críticas con dicho orden (critical theory). De ahí que no sea incorrecto incluir dentro de las teorías críticas a todos los enfoques que desafían a las corrientes mainstream. Según Cox (1981) la teoría para la resolución de problemas toma el mundo como lo encuentra, sin cuestionarse los intereses particulares que refleja las relaciones sociales y de poder y las instituciones en las que estas se organizan, partiendo de la presunción positivista de que la realidad social constituye una realidad objetiva. Su función radicaría en proponer y llevar a cabo los ajustes necesarios para suprimir o atenuar los desequilibrios y conflictos que puedan aparecer en el sistema internacional. En contraste, la teoría crítica, en su perspectiva neogramsciana, o materialismo histórico transnacional, se pregunta por sus orígenes y su proceso de cambio considerando al sistema internacional y a sus instituciones como hechos contingentes e históricos y por ende, no dados, ni naturales ni objetivos. Ello exige un estudio detallado del proceso histórico que permita entender el origen de las instituciones y la configuración de las relaciones sociales que explican y expresan el orden internacional, así como las posibilidades inmanentes para el cambio en dicho orden partiendo de las contradicciones y la correlación de fuerzas concretas en cada momento. Por consiguiente, nota bene, el conocimiento generado por el materialismo histórico transnacional no es neutral, como tampoco lo es, pese a afirmar lo contrario, el engendrado por las teorías dominantes, estando ética y políticamente comprometido con la transformación social. (Sanahuja, 2015: 165) Se trata, por estar razón, de un traslado del enfoque marxista del análisis de clase al terreno internacional. La diferencia con los análisis del marxismo ortodoxo del siglo XX, radica en que Cox (1983) reformula y readapta ciertas categorías clave de Gramsci al mismo ámbito internacional, como son la hegemonía ${ }^{20}$, la revolución

20. En 2019 publicamos un artículo específico sobre el concepto de hegemonía que quizás pueda ser de interés al lector. En él discutimos y discrepamos con algunos autores neogramscianos 
pasiva, el transformismo y el bloque histórico, que explican el porqué del fracaso revolucionario en Europa occidental y de la táctica de la toma del poder leninista en todo lugar y tiempo. (Cox, 1983) A partir de estas categorías, Cox (1981), añadiendo aportaciones del enfoque histórico-estructural de Fernando Braudel, propone el método de las estructuras históricas y se pregunta cómo emerge, se mantiene y se transforma los órdenes mundiales, cómo devienen en órdenes hegemónicos y qué fuerzas contra-hegemónicas tienen el potencial emancipatorio para que estos cambien. En la actualidad esta corriente neogramsciana, o materialista histórica transnacional, ha ido desarrollándose internacionalmente bajo equipos de trabajo como los de la Escuela de Amsterdam, o el Centro para la Economía Política Global de la Universidad de Sussex. En el Estado español, José Antonio Sanahuja, es quizás el autor más prolijo de esta corriente de pensamiento denominada sociología histórica de la globalización. Un enfoque neogramsciano que, a nuestro juicio, está complementado con tintes habermasianos.

¿Cómo se puede interpretar desde la teoría crítica neogramsciana el fracaso de EEUU en Afganistán? Teniendo en cuenta que las categorías que componen una estructura histórica como bloque histórico transnacional son, las capacidades materiales del hegemón, las ideas y las contra ideas presentes dentro de la estructura histórica, y las instituciones que le dan estabilidad, podríamos decir que EEUU como hegemón del mundo occidental ha demostrado ser incapaz, al igual que la Unión Soviética contra los muyaidines, de ganar una guerra de desgaste contra los talibanes sobre el terreno; ha sido incapaz

por privilegiar excesivamente el factor persuasivo frente a la fuerza. Molina (2019). también de inculcar los valores liberales en la sociedad afgana; y ha sido incapaz de crear unas instituciones estatales medianamente sólidas y eficientes. Estas tres insuficiencias explicarían, al menos parcialmente, el porqué del fracaso, pero además los autores de esta corriente se preguntarían acerca de qué intereses reales tenía EEUU en Afganistán, más allá del discurso dado a la opinión pública global. Estas hipotéticas preguntas estarían justificadas por la asunción de que no existe neutralidad alguna en las acciones en política internacional. Posicionarse geoestratégicamente en Asia central, con bases militares, en la frontera China, su gran rival, y de Irán, incluido en el llamado eje del mal; controlar los planes de construcción del gaseoducto que va desde Turkmenistán hasta la Inda; controlar la futura explotación minera (litio) y petrolífera; etc... estarían dentro del análisis lógico de los intereses materiales que estuvo detrás de la ocupación, sin ser incompatible con los argumentos antiterroristas esgrimidos por los distintos gobiernos estadounidenses.

Respecto al factor ideológico-religiosocultural como elemento de la sobreestructura no tenido en cuenta por EEUU a la hora de decidir cambiar el régimen político e intentar construir un Estado liberal, merece la pena citar la tesis doctoral de un refugiado afgano en España, Azizurahmán Hakami. Hakami (2010) afirma que en Afganistán hay cuatro mil mezquitas para la oración y el diálogo. La mayoría de los líderes de estas mezquitas tienen libertad de expresión para interpretar el Corán y explicarlo al pueblo. Hablan de un modo general y su palabra es respetada sin más por el pueblo. De tal modo que cuando estos líderes ordenan algo, el pueblo obedece sin buscar justificación ya que la propia palabra del líder es suficiente ra- 
zonamiento. La creencia de los afganos es que los líderes religiosos son Soldados de Dios, su propia sombra, y han sido enviados para guiarlos. Un enfrentamiento contra ellos significa enfrentarse a Dios directamente. (Hakami, 2010: 315-316) De ahí que la población afgana, a pesar de su heterogeneidad étnica, fuera dejándose convencer tácitamente por los talibanes como etnia fundamentalista hegemónica, la pastún. Desde el presidente El Afgani a fines del siglo XIX, el islam fue bien interiorizado por las diferentes etnias al igual que el anti imperialismo occidental. Este anti imperialismo unía de forma identitaria a todas las etnias en torno al islam, desapareciendo momentáneamente las diferencias entre chiíes y suníes y las luchas internas inter étnicas. Esto explicaría las reacciones psicológicas de la población afgana contra todas las agencias extranjeras en Kabul durante algunos momentos de la ocupación estadounidense mencionadas anteriormente a colación del libro de Mónica Bernabé. Los talibanes, creación del gobierno pakistaní con el apoyo de EEUU y Arabia Saudí para contener al comunismo y al chiísmo respectivamente, fueron formados en el fundamentalismo y aspiraban a la unidad política desde el principio en pro de la estabilidad de Afganistán, a diferencia de los muyaidines que eran criticados por su sectarismo, su falta de formación en el Corán y sus abusos de poder. (Hakami, 2010: 325)

Con relación a los posibles cambios en la distribución del poder en el orden mundial a colación de la derrota de EEUU, los efectos están por verse en el mediano plazo, pero todo indica una notoria pérdida de hegemonía, no solo material -2 billones de dólares perdidos y 2.324 soldados muertos- sino sobre todo moral tras comprobarse la hipocresía del doble discurso, así como el abandono de la población afgana a su suerte, culpándolos a ellos mismos de su propia desgracia. Para finalizar, esta escuela neogramsciana se interrogaría si existen contra tendencias emancipatorias relacionadas con el conflicto en Afganistán. Si bien algunos otros enfoques críticos $^{21}$ del orden mundial, pudieran subliminalmente considerar a los propios talibanes como un movimiento social contra hegemónico que ha liberado a la población afgana del imperialismo occidental, la corriente neogramsciana podría percibir, más bien, a los talibanes como un contra movimiento reaccionario y antimoderno al negar derechos individuales fundamentales adquiridos, sobre todo en la población femenina.

Respecto a la otra vertiente de la teoría crítica, la Escuela de Francfort, -que analizamos indirectamente a través de Sanahuja-, si bien fue Max Horkheimer quien le puso el nombre en contraposición al positivismo en las ciencias sociales, es el pensamiento de Jürgen Habermas el que vincula a dicha Escuela con la teoría de las relaciones internacionales. La distinción no es baladí, pues, a nuestro entender, mientras la primera generación tenía una orientación neomarxista, el enfoque habermasiano puede definirse ya como postmarxista. Esto explicaría la influencia predominante de Kant en los autores habermasianos que se alejan de los análisis rupturistas y que simpatizan con algunos de los sub enfoques liberales mencionados anteriormente, como el republicano, así como con la socialdemocracia como proyecto político deseable. Un autor relevante de esta corriente es Andrew Linklater.

21. Nos referimos a ciertas teorías de índole conspiratorias como la de Thierry Meyssan vinculada a gobiernos como el ruso de Vladimir Putin. 
En síntesis, este enfoque kantiano de la teoría crítica se caracteriza por un decidido compromiso con un universalismo cosmopolita que reconozca y valore la diversidad a través de una ética del discurso. Esta asume que la deliberación ciudadana de los asuntos públicos y las cuestiones morales pueden ser resueltas a través del diálogo sin exclusiones y sin privilegios de partida. Esta teoría, llamada de la acción comunicativa, afirma la capacidad de los individuos para alcanzar consensos a través de una interacción significativa basada en la deliberación, argumentación y debate racional. (Sanahuja, 2015: 181) La asunción de la propuesta cosmopolita radica en que, para Habermas, la globalización ha ampliado las posibilidades de daños transnacionales que los Estados se muestran incapaces de enfrentar, y de asegurar las necesidades básicas de su ciudadanía en cuanto a justicia social, bienestar, y seguridad física. De ahí la necesidad práctica para la creación de una comunidad política post-nacional.

$\mathrm{Si}$ reflexionamos sobre el conflicto en Afganistán, desde este enfoque, se podría argumentar que mediante la deliberación y el convencimiento racional desde abajo se podría haber ganado progresivamente a la población afgana. A través de una ética política desde la transparencia y la empatía, -como intentó sucintamente llevar a cabo el general Stanley McChrystal- se debería haber demostrado que las instituciones liberales protegerían los derechos de los más vulnerables y mejorarían claramente la calidad de vida de la población en su conjunto. Sería algo así como una transculturación ética y convincente contra el dogmatismo religioso islámico y no, como lo intentó hacer la Unión Soviética, mediante la imposición y la violencia institucional.
Estas dos visiones que definen strictu sensu a la teoría crítica de las relaciones internacionales, es decir, la orientación del materialismo histórico transnacional o neogramscianismo y la óptica cosmopolita o habermasiana, son complementados por otras perspectivas que deben incorporarse dentro de las teorías críticas en su acepción general como son las teorías feministas y el enfoque decolonial.

Las teorías feministas buscan el cambio emancipatorio en el orden mundial apostando por la igualdad entre mujeres y hombres, en cuanto a roles, normas, instituciones, participación y reconocimiento. (Sanahuja, 2018:117) La teoría feminista se incorpora a las relaciones internacionales a finales de la década de los ochenta y tiene orientaciones heterogéneas. El feminismo liberal, desde la propia Revolución Francesa, a través de figuras como Olympe de Gouges, y en la actualidad autoras como J. Ann Tickner, V. Spike Peterson, Anne Sisson, o Cynthia Enloe, entienden la desigualdad de hombres y mujeres como una violación de los principios liberales fundamentales, siendo su objetivo primordial aplicar los principios de libertad, igualdad y justicia, a ambos sexos. Trasladado al terreno internacional, este sub enfoque apuesta en primer lugar por la supresión de los obstáculos jurídicos que han negado a las mujeres las mismas oportunidades que a los hombres. ¿Dónde están las mujeres? se preguntan las feministas liberales. (Sanahuja, 2015: 253) Frente a esta ruta de la igualdad, el feminismo radical propone la ruta de la diferencia. Estas autoras como Gayle Rubin, Sandra Whitworth, Jacqui True, Marysia Zalewski, distinguen a los hombres de las mujeres por su espíritu de dominación, racionalidad y capacidad ejecutora, contra el pacifismo, sensibilidad y empatía de 
las mujeres. Estas cualidades femeninas serían superiores a los atributos masculinos derivándose de ello la pertinencia de insertar su visión en las instituciones y en las relaciones internacionales. Ello permitiría reconfigurar el orden mundial en clave pacifista. El feminismo radical en las relaciones internacionales amplía el eslogan "lo personal es político" a "lo personal es internacional" para procurar recuperar la esfera privada como un espacio político y subrayar así el modo en que el poder en esta esfera permea a la otra, a la internacional. (Sanahuja, 2015: 258) A diferencia del feminismo liberal y radical, el feminismo postcolonial -Gayatri Spivak, Homi Bhabha, o Chandra Mohanty- critica a los anteriores al tratar a las mujeres como una categoría homogénea, ignorando las diferencias culturales, de clase, de raza, y de ubicación geográfica. Ello explica su interés por la identidad y la cultura, la raza y el género. (Sanahuja, 2015: 266)

$\mathrm{Si}$ se intenta especular desde los sub enfoques feministas sobre Afganistán, podríamos aventurarnos a aseverar que las mujeres han sido instrumentalizadas por parte de todos los bandos para luego ser abandonadas a su suerte por las potencias occidentales. Desde un punto de vista liberal, las mujeres apenas fueron insertadas en las instituciones creadas durante la ocupación. Siempre fueron una minoría incómoda. Además, en el ámbito privado, la Sharia seguía normalizando la vida familiar en desmedro de la igualdad de derechos. Desde la aproximación radical, la crítica a EEUU, a las instituciones internacionales, y a los gobiernos afganos post talibanes, sería más contundente aún ya que las mujeres fueron obviadas en los procesos de negociación aceptando los condicionantes impuestos por los talibanes desde el primer momento. Esto significa que la tesis sobre la superioridad femenina a la hora de abordar los problemas internacionales con relación a los procesos de paz queda automáticamente descartada. Desde el feminismo post colonial el asunto se complica aún más ya que la invasión y la ocupación es vista como un accionar neocolonial contra el que había que luchar. Un camino llevado a cabo precisamente por los propios talibanes en una suerte de lucha por la liberación nacional. Si a ello sumamos la apuesta de la perspectiva post colonial de respetar y comprender las diferencias culturales, quitándonos el filtro occidental, este sub enfoque se enfrenta al dilema de cómo defender los derechos de la mujer afgana al mismo tiempo que se aboga por el respeto y comprensión a la particularidad cultural de los diferentes pueblos de Afganistán. Si extendemos este sub enfoque feminista al ámbito de las relaciones internacionales, esta corriente post colonial reivindica lo específico y subalterno, en pro del particularismo y el relativismo frente al universalismo de las teorías anteriores. Estas teorías universalistas mencionadas son criticadas por ser teleológicas. En esto el enfoque decolonial, mutatis mutandis, coincide con el postmodernismo, además comparten el método deconstructivo del análisis al pretender desnudar la ideología colonial y orientalista que están detrás de las relaciones de poder en el ámbito internacional. (Sanahuja, 2018: 119) La tarea primordial consistiría en la revisión crítica para descolonizar la teoría y la disciplina de las relaciones internacionales a partir del reconocimiento de otras perspectivas, tradiciones y teorías no occidentales. No nos queda espacio para presentar las diferencias entre los autores postcoloniales por lo que estas serán tratadas de forma específica en una próxima investigación. Algunos autores de referencia son, Boa- 
ventura de Sousa Santos, Enrique Dussel, Walter Mignolo, Aníbal Quijano, o Ramón Grosfoquel.

\section{Conclusión}

Se ha podido comprobar que el problema geopolítico de Afganistán, así como cualquier otro, puede ser analizado desde diferentes perspectivas en función de los distintos posicionamientos epistemológicos y de los intereses que se hallan detrás de los mismos. No existe aquello que algunos Ilaman la neutralidad teórica. Empero, a la hora de la verdad, cuando los decisores políticos analizan y toman medidas suelen echar mano de diferentes sub enfoques dentro del troncal en una suerte de eclecticismo pragmático, buscando efectividad y resultados. En el caso de Afganistán, son las teorías neorrealistas y neoliberales, representadas por republicanos y demócratas, las que confluyen eclécticamente en la forma del neoconservadurismo en pro del accionar en la política internacional estadounidense. Un accionar al estilo imperial, en términos negristas y gramscianos, que ha buscado de forma infructuosa combinar las ganancias materiales derivadas del control del territorio afgano, con el consenso y la generación de hegemonía en torno a la venta ideológica del proyecto civilizatorio liberal y democrático. Pienso que el fracaso de esta segunda variable hegemónica, que condicionó la posibilidad de la primera -la material-, se debió en primer lugar al desconocimiento de los referentes culturales e identitarios de la mayoría de las etnias afganas y al papel de sus intelectuales orgánicos como elemento de la superestructura política. A esto hay que añadir la inseguridad permanente por los continuos atentados terroristas que mermaron la moral de la población afgana y la corrupción generalizada de las instituciones y de la propia sociedad civil obligada a adaptarse a una situación de guerra sin fin.

Ahora bien, al igual que ocurre con las teorías neorrealistas y neoliberales, las teorías críticas pueden ser compatibles hasta cierto punto entre sí, de tal manera que el eclecticismo no solo debe permitirse, sino que puede ser más efectivo y táctico en el terreno práctico de las luchas de los pueblos y de los movimientos sociales que aspiran a transformar el orden social mundial. El dogmatismo y el sectarismo han sido históricamente los dos obstáculos permanentes más relevantes en los Estados subalternos, los movimientos sociales, las organizaciones políticas y los teóricos sociales para poder articular fuerzas contra hegemónicas poderosas y estables en el tiempo. De ahí que el eclecticismo epistemológico relativo, -es decir, dejando afuera, quizás, algunas visiones idealistas insertas en las teorías críticas que pudieran ser incompatibles con el materialismo-, pueda ser un antídoto interesante contra esos males en un contexto de crisis hegemónica del proyecto político, económico y cultural de la globalización liberal. Un eclecticismo materialista entendido epistemológicamente como método instrumental o caja de herramientas que permita analizar una realidad internacional cada vez más compleja e incorporando la ética procesual como modus operandi para el planteamiento de cualquier proyecto emancipatorio. Esto quiere decir que la crítica y la democracia, en sentido profundo y radical, deben ser variables independientes de cualquier proyecto emancipador evitando, a toda costa, reproducir ontológicamente auto- 
ritarismos pasados que no generan hegemonía transnacional. Un eclecticismo materialista deontológico, superando las limitaciones democráticas de los populismos de izquierda laclausianos, que admita de forma inter seccional, las miradas feministas, post coloniales, neogramscianas, habermasianas, realistas críticas ${ }^{22}$, pero también, verbigracia, negristas ${ }^{23}$, y ecológicas. Para finalizar dejaré algunas preguntas sobre el tapete para seguir reflexionando a posteriori: ¿Cuáles son los retos a los que se enfrenta las teorías críticas de las relaciones internacionales para salir de la subalternidad epistemológica? ¿Cómo pueden superarse y complementarse las visiones sectoriales? ¿Cómo estas teorías podrían vincularse a la praxis de los movimientos sociales transnacionalmente? ¿Cómo se podría insertar hegemónicamente la interculturalidad y el diálogo entre "civilizaciones" en la agenda internacional frente a las teorías predominantes del choque cultural?

\section{Bibliografía}

Acemoglu, D. (Aug 20, 2021) Why NationBuilding Failded in Afghanistan. Project Syndicate. https://www. project-syndicate. org/commentary/afghanistan-top-downstate-building-failed-again-by-daron-acemoglu-2021-08 (Consulta: 10/09/2021)

ACNUR (12 de octubre, 2021) La crisis en Afganistán se agrava con la bajada de las temperaturas. Naciones Unidas [Nota informativa]. https://news.un.org/ es/story/2021/10/1498282 (Consulta: 20/10/2021)

22. Por influencia de Edwar Carr (2004).

23. De Toni Negri, autor de Imperio (2002).
Aznar, J.M. (10 de septiembre, 2021) Entrevista a José María Aznar por John Muller. ABC. https://www.abc.es/espana/ abci-jose-maria-aznar-11-s-mas-atentado-acto-guerra-202109100053_video. html (Consulta:10/09/2021)

Barbé, E. y Soriano, J.P. (2015) "Del debate neorrealismo-neoliberalismo a la (Re) construcción del discurso dominante en relaciones internacionales", en C. del Arenal y J.A. Sanahuja (coords.) Teorías de las Relaciones Internacionales, Madrid, Tecnos, p.e. 127-156.

Bernabé, M. (2012) Afganistán: Crónica de una ficción, Barcelona, Debate.

Carr, E.H. (2004) La crisis de los veinte años (1919-1939), Madrid, Catarata.

Arenal, C. y Sanahuja, J.A. (Coords.) (2015) Teorías de las relaciones internacionales, Madrid, Tecnos.

Cox, R. (1981) "Social Forces, States and World Orders: Beyond International Relations Theory" en Millennium: Journal of International Studies, vol.10, $\mathrm{n}^{\circ} 2$, p.e.126-155. https://journals.sagepub. com/doi/abs/10.1177/03058298810100 020501

Cox, R. (1983) "Gramsci, Hegemony and Internacional Relations: An Essay in Method", en Millennium: Journal of International Studies, vol.12, n², p.e. 162-175. https://journals.sagepub.com/doi/abs/10.1 177/03058298830120020701

Gilpin, R. (1981) War and Change in World Politics, Cambridge, Cambridge University Press.

Gramsci, A. (1981) Cuadernos de la cárcel, México, Era.

Grasa, R. (2015) "Neoliberalismo e institucionalismo. La construcción del libe- 
ralismo como teoría sistémica internacional", en C. del Arenal y J.A. Sanahuja (coords.) Teorías de las Relaciones Internacionales, Madrid, Tecnos, p.e. 97-125.

Hakami, A. (2010) Crisis política y económica en Afganistán [Tesis de doctorado, Universidad Complutense de Madrid]. https://eprints.ucm.es/id/eprint/11189/

Hardt y Negri. (2002) Imperio, Barcelona, Paidós.

Hardt y Negri. (2007) La Multitud y la Guerra, México, Era.

Hobsbawm, E. (2003) Historia del Siglo $X X$, Barcelona, Crítica.

Huntington, S. (2001) El Choque de las civilizaciones y la reconfiguración del orden mundial, Buenos Aires, Paidós.

Independent (August, 16, 2021) Bush rompe el silencio sobre la retirada de Afganistán e insiste en que el 'sacrificio' no fue en vano. Independent. https://www. independentespanol.com/politica/ee-uu/ afganistan-bush-tropas-talibanes-bidenb1904268.html (Consulta: 04/09/2021)

Keohane, R. (1988) "International Institucions: Two Approaches", en International Studies Quarterly, vol. 32, nº4, p.e. 379396.

Kissinger, H. (August 25, 2021) Why America failed in Afghanistan? The Economist. https://www.economist.com/by-invitation/2021/08/25/henry-kissinger-on-whyamerica-failed-in-afghanistan (Consulta: 10/09/2021)

Miller, L. (November 17, 2021) Afghanistan 2001-2021: U.S. Policy Lessons Learned. Internacional Crisis Group. [Testimonio] https://www.crisisgroup.org/ asia/south-asia/afghanistan/afghanistan2001-2021-us-policy-lessons-learned (Consulta: 27/11/2021)
Molina, E.M (2018) La Filosofía Política de Toni Negri, Sevilla, Atrapasueños.

Molina, E.M (2019) "El concepto de hegemonía en las relaciones internacionales: una crítica a Andreas Antoniades" en Revista Internacional de Pensamiento Político, Vol.14, p.e. 427-436.

Moravcsik, A. (1997) "Taking Preferences Seriously: A Liberal Theory of International Politics", en International Organization, vol.51, n4, p.e. 513-553.

Moure, L. (2015) "El realismo en la teoría de las relaciones internacionales: génesis, evolución y aportaciones actuales", en C. del Arenal y J.A. Sanahuja (coords.) Teorías de las Relaciones Internacionales, Madrid, Tecnos, p.e. 61-95.

Said, E. (16 de octubre, 2001) El choque de ignorancias. El País. https:// elpais.com/diario/2001/10/16/opinion/1003183207_850215.html

Salomon, M. (2002) "La teoría de las relaciones internacionales en los albores del siglo XXI: diálogo, disidencia, aproximaciones", Revista Electrónica de Estudios Internacionales (REEI), vol. 4, p.e. 1-59. http://www.reei.org/index.php/revista/ num4/articulos/teoria-relaciones-internacionales-albores-siglo-xxi-dialogo-disidencia-aproximaciones

RNE. (18 de agosto, 2021) Entrevista a Joseph Borrell. RTVE. https://www. rtve.es/noticias/20210818/borrell-ocurrido-afganistan-derrota-del-mundooccidental/2160740.shtml (Consulta: 25/08/2021)

Sanahuja, J.A. (2015) "Los Desafíos de la Teoría Crítica de las Relaciones Internacionales", en C. del Arenal y J.A. Sanahuja (coords.) Teorías de las Relaciones Internacionales, Madrid, Tecnos, p.e. 157-188. 
Sanahuja, J.A. (2018) "Reflexividad, Emancipación y Universalismo: Cartografías de la Teoría de las Relaciones Internacionales" en Revista Española de Derecho Internacional, vol. 70/2, julio-diciembre, p.e.101-125. http://www.revista-redi.es/ wp-content/uploads/2018/08/5_estudios_ reflexividad_emancipacion_universalismo_sanahuja-1.pdf

Soriano, R. y Mora, J.J. (2006) Los Neoconservadores y la Doctrina Bush, Sevilla, Aconcagua.

The White House. (16 de agosto, 2021) Declaración del presidente Biden sobre Afganistán. The White House. https:// www. whitehouse.gov/es/prensa/discursos-presidenciales/2021/08/16/declaraciones-del-presidente-biden-sobre-afganistan/ (Consulta: 25/08/2021)

U.S Departament of State. (2020) Agreement for Bringing Peace to Afghanistan between the Islamic Emirate of Afghanistan which is not recognized by the United States as a state and is known as the Taliban and the United States of America. Recuperado de https://www.state.gov/wpcontent/uploads/2020/02/Agreement-ForBringing-Peace-to-Afghanistan-02.29.20. pdf (Consulta: 25/08/2021)

Watson Institute. (2021) Cost of War. Recuperado de https://watson.brown.edu/ costsofwar/figures/2021/WarDeathToll (Consulta: 10/09/2021) 
